\title{
The Impoverished Brain: Disparities in Maternal Education Affect the Neural Response to Sound
}

\author{
Erika Skoe, ${ }^{1,3}$ Jennifer Krizman, ${ }^{1,2,3}$ and Nina Kraus ${ }^{1,3,4,5,6}$ \\ ${ }^{1}$ Auditory Neuroscience Laboratory, ${ }^{2}$ Bilingualism and Psycholinguistics Research Group, ${ }^{3}$ Department of Communication Sciences, ${ }^{4}$ Institute for \\ Neuroscience, ${ }^{5}$ Department of Neurobiology and Physiology, and ${ }^{6}$ Department of Otolaryngology, Northwestern University, Evanston, Illinois 60208
}

Despite the prevalence of poverty worldwide, little is known about how early socioeconomic adversity affects auditory brain function. Socioeconomically disadvantaged children are underexposed to linguistically and cognitively stimulating environments and overexposed to environmental toxins, including noise pollution. This kind of sensory impoverishment, we theorize, has extensive repercussions on how the brain processes sound. To characterize how this impoverishment affects auditory brain function, we compared two groups of normal-hearing human adolescents who attended the same schools and who were matched in age, sex, and ethnicity, but differed in their maternal education level, a correlate of socioeconomic status (SES). In addition to lower literacy levels and cognitive abilities, adolescents from lower maternal education backgrounds were found to have noisier neural activity than their classmates, as reflected by greater activity in the absence of auditory stimulation. Additionally, in the lower maternal education group, the neural response to speech was more erratic over repeated stimulation, with lower fidelity to the input signal. These weaker, more variable, and noisier responses are suggestive of an inefficient auditory system. By studying SES within a neuroscientific framework, we have the potential to expand our understanding of how experience molds the brain, in addition to informing intervention research aimed at closing the achievement gap between high-SES and low-SES children.

\section{Introduction}

Auditory brain function is shaped by the environment (Blakemore and Cooper, 1970; Hyde and Knudsen, 2002). Environments that are less acoustically and/or socially stimulating can affect the neural systems that underlie auditory perception, leading to delayed auditory development (Eggermont et al., 1997; Chang and Merzenich, 2003), altered neural responses (Sanes and Constantine-Paton, 1983, 1985; Poon and Chen, 1992; Zhang et al., 2002; Hauber et al., 2013), and hyperactivity within the auditory cortex and midbrain (Noreña and Eggermont, 2003; Mulders and Robertson, 2013). The impact of sensory deprivation has been well studied in laboratory animals and humans (Roberts et al., 1998; Kral and Eggermont, 2007; Conway et al., 2009); yet, comparatively little is known about how normalhearing human populations are affected by auditory impoverish-

Received May 17, 2013; revised Sept. 8, 2013; accepted Sept. 12, 2013.

Author contributions: E.S., J.K., and N.K. designed research; E.S. and J.K. performed research; E.S. contributed unpublished reagents/analytic tools; E.S. analyzed data; E.S., J.K., and N.K. wrote the paper.

This work was supported by Supported by Northwestern University Knowles Hearing Center, NSF SMA-1015614, and the Mathers Foundation. We thank Vance Gao for his help with data analysis, as well as Douglas Savitsky, Trent Nicol, Ellie Thompson, and Travis White-Schwoch for their comments on an earlier draft of this manuscript. We also thank the students and their families for participating and the schools and teachers, especially Kate Johnston, for their support of the project. We also extend our appreciation to Rafael Escobedo-Quiroz and the other members of the Auditory Neuroscience Laboratory, past and present, for their help in data collection and participant recruitment. The authors declare no competing financial interests.

Correspondence should be addressed to Nina Kraus, PhD, Northwestern University, 2240 Campus Drive, Evanston IL, 60208. E-mail: nkraus@northwestern.edu.

E. Skoe's present address: Department of Speech, Language, and Hearing Sciences, Department of Psychology Affiliate, Cognitive Science Program, University of Connecticut, Storrs, CT 06269

DOI:10.1523/JNEUROSCI.2102-13.2013

Copyright $\odot 2013$ the authors $\quad 0270-6474 / 13 / 3317221-11 \$ 15.00 / 0$ ment, conditions where acoustic stimulation is reduced but not absent. Here we examine the link between auditory function and environmental factors in adolescents with varying degrees of maternal education.

Maternal education, income, occupation, and social status combine to predict a child's socioeconomic status (SES), with maternal education being one of the strongest indicators of SES in studies of child development (Hoff et al., 2012). In addition to reduced access to nutrient-rich food and greater exposure to environmental toxins (Evans and Kantrowitz, 2002), socioeconomically disadvantaged children receive less linguistic and cognitive stimulation (e.g., fewer and simpler words) from their caregivers than their more privileged counterparts (Hart and Risley, 1995; Bradley and Corwyn, 2002; Rowe and Goldin-Meadow, 2009; Sheridan et al., 2012; Cartmill et al., 2013). This, combined with greater exposure to unstructured auditory stimulation, as the result of increased noise exposure (Evans and Kantrowitz, 2002), limits opportunities for high-quality learning experiences. Decades of research indicate that this reduced environmental stimulation has profound effects on academic outcomes and executive function (Brooks-Gunn and Duncan, 1997; Hackman and Farah, 2009; Raizada and Kishiyama, 2010). A recent wave of neuroscientific research has further endorsed the idea that sociocultural factors influence brain structure and function (Otero, 1997; Tomarken et al., 2004; Noble et al., 2007, 2012; D’Angiulli et al., 2008; Raizada et al., 2008; Kishiyama et al., 2009; Stevens et al., 2009; Hanson et al., 2011; Jednoróg et al., 2012; Sheridan et al., 2012; for review, see Lipina and Posner, 2012). This work has revealed that the neurobiological systems mediating higherorder functions like language, memory, and executive function- 
including the perisylvian region, hippocampus, and prefrontal cortex - are especially sensitive to disparities in SES (Noble et al., 2005, 2006, 2007, 2012; Raizada et al., 2008; Evans and Schamberg, 2009; Kishiyama et al., 2009; Hackman et al., 2010; Hanson et al., 2011; Sheridan et al., 2012). Specific to auditory processing, electrophysiological evidence suggests that low-SES children have increased difficulty suppressing irrelevant auditory input during an active-listening, selective-attention paradigm (D'Angiulli et al., 2008; Stevens et al., 2009; Neville et al., 2013). But the question remains as to whether impoverished auditory environments affect automatic sound processing in normal-hearing individuals. Drawing on studies of animals raised in altered environments, we hypothesized that limited environmental stimulation that accompanies socioeconomic disadvantages, in addition to affecting higher-order functions, compromises how the brain represents auditory signals, resulting in differences in auditory neural function even when attentional factors are removed.

To test our hypothesis, we assessed brain activity both in response to, and in the absence of, auditory input. We recorded auditory brainstem responses (ABRs) using a passive listening paradigm in a cohort of normal-hearing adolescents, grouping students based on the highest education level achieved by their mother. Passive electrophysiological recordings have been used extensively to study how the brainstem is fine-tuned by experience (Krishnan et al., 2005; Kraus and Chandrasekaran, 2010). This work has revealed that ABRs can, even under passive conditions, tap into how the nervous system was shaped by previous active engagement with sound. We predicted that adolescents with lower maternal education (no postsecondary education) would have lower literacy levels and working memory ability (Noble et al., 2007; Evans and Schamberg, 2009), coupled with weaker brainstem function than schoolmates with higher maternal education. This weakening, we posited, would translate into more inconsistent ABRs (Hornickel and Kraus, 2013), less robust responses to the input signal (Banai et al., 2009), and an altered resting brain state (Otero, 1997; Tomarken et al., 2004; Marshall et al., 2008).

\section{Materials and Methods}

Data were collected as part of a larger ongoing study on adolescent brain development currently underway in the Auditory Neuroscience Laboratory at Northwestern University. Informed written assent was obtained from each participant. Parents/guardians provided informed consent and also completed a questionnaire assessing health, education, language history, and ethnic/racial background. All experimental procedures were approved by Northwestern University's Institutional Review Board.

\section{Participants}

Inclusion criteria

All students were incoming or current ninth graders at the time of testing and met the following study inclusion criteria: (1) no history of poor maternal health during pregnancy (e.g., smoking, alcohol consumption, drugs, etc.), (2) normal birth weight, (3) no indication of a neurological disorder, (4) normal audiological status as confirmed by otoscopic examination, distortion product otoacoustic emissions, as well as air and bone conduction audiometry (pure tone averages thresholds $>20 \mathrm{~dB}$ hearing level), and (5) an IQ $>80$ (Wechsler Abbreviated Scale of Intelligence Vocabulary and Matrix Reasoning subtests). In addition, participants were excluded if English was not their primary language, if either parent was educated outside of the United States, if the participant lived outside of the United States for $>6$ months, or if their primary caregivers were not biological relatives. The current analysis includes 66 participants (average age, 14.57 years; 30 females) enrolled in three high schools within the Chicago Public School system.
Table 1. Distribution of maternal educational achievement within the lowMaternalEd and high-MaternalEd groups

\begin{tabular}{lc}
\hline Maternal education & Number of participants \\
\hline Low-MaternalEd & 33 \\
Less than high school diploma & 6 \\
High school diploma/GED & 27 \\
High-MaternalEd & 33 \\
Some college, no degree & 3 \\
Vocational degree & 2 \\
College degree (level not specified) & 4 \\
Associate's degree & 12 \\
Bachelor's degree & 5 \\
Master's degree & 6 \\
Doctoral degree & 1 \\
\hline
\end{tabular}

Table 2. The low- and high-MaternalEd groups were matched with respect to age, hearing thresholds (pure tone average for right and left ear), and birth weight

\begin{tabular}{|c|c|c|c|c|}
\hline & Low-MaternalEd & High-MaternalEd & $t$ & $\begin{array}{l}\text { Significance } \\
\text { (two-tailed) }\end{array}$ \\
\hline Age (years) & Mean, 14.52; SD, 0.51 & Mean, $14.58 ;$ SD, 0.50 & -0.49 & 0.63 \\
\hline $\begin{array}{l}\text { Hearing thresholds } \\
\text { (dB hearing level) }\end{array}$ & Mean, 6.79; SD, 4.55 & Mean, 5.55; SD, 4.77 & 1.08 & 0.28 \\
\hline Birth weight (lb) ${ }^{a}$ & Mean, 7.15; SD, 1.22 & Mean, 7.47; SD, 1.48 & -0.85 & 0.40 \\
\hline
\end{tabular}

${ }^{a}$ Information not available on 11 participants.

\section{Participant groups}

As part of the participant history questionnaire, the parent/guardian indicated the highest level of education achieved by the biological mother by selecting one of four possible categories: middle school, high school/ GED (General Education Development) equivalent, college, graduate/ professional. Participants were then divided into two groups that we refer to as the "low" and "high" maternal education groups (hereafter abbreviated low-MaternalEd and high-MaternalEd; $n=33$ each, 15 females/ group). The low-MaternalEd group included participants whose mothers had a high school education $(n=27)$ or less $(n=6)$. If the mother completed some postsecondary schooling, the participant was placed in the high-MaternalEd group. For 46 participants, additional information on the exact years and nature of the postsecondary education was obtained (low, 20; high, 26). For these 46 participants, the average years of maternal education was calculated to be $11.40 \pm 2.04$ years for the low group and $14.96 \pm 1.82$ years for the high group, with 12 years corresponding to the completion of senior year of high school (independent $t$ test, $t_{(44)}=-6.26, p<0.001$; Table 1 ).

In addition to differing in maternal education, the two groups also differed in paternal education (low, $11.75 \pm 2.86$ years; high, $13.57 \pm$ $2.86, t_{(41)}=-2.22, p=0.03$ ) and parental occupation (maternal: Kolmogorov-Smirnov $Z=1.39, p=0.04$; paternal: $Z=1.81, p=0.003$ ). Maternal and paternal occupations were coded into eight categories according to the General Social Survey (http://www3.norc.org/gss+ website/). These categories were as follows: professional or technical, higher administration, clerical, sales, service, skilled, semiskilled, and unskilled work.

The groups were created to be matched on variables that have been previously shown to influence auditory function, including age (Salamy et al., 1975), sex (Krizman et al., 2012a), language background (Krizman et al., 2012b), and hearing thresholds (Hood, 1998; Anderson et al., 2013b; Tables 2, 3). In addition, the groups were created to have an equivalent sample of participants from the low and high groups from each of the three schools $(Z=0.246, p=1.00)$. Another factor that was controlled was race/ethnicity, as assessed by parental report. The ethnic distribution was matched between groups $(Z=0.57, p=0.89$; two participants opted not to respond), with Hispanics representing a large majority of both the low and high groups ( 84 vs $70 \%$, respectively). For the low group, the remaining $16 \%$ identified as African-American. In the high group, among the non-Hispanics, the distribution was 24, 3, and 3\% for African-American, Caucasian, and Asian categories, respectively. 
Table 3. Self-reported age of acquisition and extent of current exposure to English and Spanish for the low-MaternalEd and high-MaternalEd groups ${ }^{a}$

\begin{tabular}{llll} 
English & Spanish & \\
\cline { 3 - 3 } $\begin{array}{l}\text { Age of } \\
\text { acquisition }\end{array}$ & Age of & \\
(years) & Current exposure & acquisition & \\
& (years) & Current exposure
\end{tabular}

Low-MaternalEd 3.13 (SD, 2.35) 75.75\% (SD, 1.21\%) 3.28 (SD, 2.42) 20.33\% (SD, 20.39\%)

High-MaternalEd 2.31 (SD, 2.35) 81.84\% (SD, 1.17\%) 3.74 (SD, 2.96) 14.67\% (SD, 17.63\%) a Language background was assessed using the Language Experience and Proficiency Questionnaire (LEAP-Q; Mar-
ian et al., 2007). The low and high groups did not differ in terms of their current daily exposure to English or Spanish, nor did they differ in the age that English and/or Spanish was acquired. All comparisons, $p>0.05$.

Given that ethnicity and school environment are socioeconomic cofactors (Brooks-Gunn et al., 1996), we were careful to control for both. Through this careful matching, we were able to minimize heterogeneity within our sample, allowing us to more specifically address how early auditory experiences, as measured by maternal education, influence how the brain represents sound.

\section{Reading and executive function testing}

In addition to obtaining IQ assessments, students were administered a standardized, age-normed test battery of reading ability and executive function (working memory).

\section{Test of Silent Word Reading Fluency (TOSWRF)}

A timed test ( $3 \mathrm{~min}$ ) in which students must identify word boundaries in a row of letters. There are no spaces between words and every letter is part of a word (e.g., nospacesbetweenwords).

\section{Test of Word Reading Efficiency (TOWRE)}

A measure of real-word and nonword reading ability in a timed format. Students are given $45 \mathrm{~s}$ to accurately pronounce as many items in a list as possible. Real-word and nonword scores are combined into a final composite score.

\section{Woodcock Johnson}

The test battery included multiple subtests of the Woodcock Johnson (WJII) Achievement and the Cognitive Abilities tests (Woodcock et al., 2001).

Basic Reading Composite Score. Measures real-word and nonword reading ability in a nontimed format. The subtest represents a composite of the Letter-Word Identification (real-word) and Word Attack (nonword) subtests.

Spelling. Words are spelled from dictation.

Numbers Reversed. A series of orally presented numbers (1-9) must be repeated in reverse order in this digit span test (e.g., the series $4,7,1$ must be repeated $1,7,4$ ).

Auditory Working Memory. The student is asked to reorder an orally presented sequence containing digits and objects (e.g., cat, 4, turtle, 7, 9, pear) first repeating the objects and then the digits, each in the order presented (e.g., cat, turtle, pear; 4, 7, 9).

\section{ABRs}

The auditory brainstem is a communication hub within the CNS that serves as a bridge between the cochlea and the cerebral cortex. ABRs, which can be measured under passive listening conditions, reflect past and ongoing sensory experiences and relate to linguistic and cognitive function, as seen in auditory experts and populations with average-tohigher SES (for review, see Kraus and Chandrasekaran, 2010; Skoe and Kraus, 2010; Kraus et al., 2012).

Procedures for measuring ABRs followed published guidelines (Skoe and Kraus, 2010). The collection protocol lasted $\sim 20 \mathrm{~min}$, during which participants sat comfortably watching a self-selected subtitled movie, while the ABR to 6000 stimulus presentations was passively collected. As is typical of most ABR paradigms, participants were instructed to attend to the movie and ignore the stimulus.

\section{Stimulus}

ABRs were recorded to a $40 \mathrm{~ms}$ synthesized [da] stimulus that was presented at a rapid rate $(10.9 / \mathrm{s})$ to the right ear at $80 \mathrm{~dB}$ SPL through an earphone placed in the ear canal. The left ear remained unblocked, making the movie sound track audible ( $<40 \mathrm{~dB}$ SPL) yet not intense enough to mask the stimulus.

This particular syllable was chosen because it is common to many languages of the world (Maddieson, 1984), its acoustic characteristics cause it to be perceptually challenging (i.e., a short syllable containing rapid changes; Tallal and Stark, 1981), and it has been used routinely to study auditory function in other populations (Banai et al., 2009; Krizman et al., 2012a). The stimulus begins with an initial noise burst that is followed by a formant transition period, during which the fundamental frequency $\left(F_{0}\right)$ and lower three formants $\left(F_{1}, F_{2}, F_{3}\right)$ ramp linearly $\left(F_{0}\right.$, $\left.103-125 \mathrm{~Hz} ; F_{1}, 264-656 \mathrm{~Hz} ; F_{2}, 1700-1240 \mathrm{~Hz} ; \mathrm{F}_{3}, 2580-2500 \mathrm{~Hz}\right)$.

\section{Recording parameters}

ABRs were recorded with a customized recording protocol within the AEP (auditory evoked potentials) module of the Navigator Pro, an evoked potential system (Natus Medical). Ag/AgCl-plated electrodes were placed at the vertex of the head $(\mathrm{Cz}$, active electrode), right ear (reference electrode), and high forehead (ground electrode). Responses were online bandpass filtered from 100 to $2000 \mathrm{~Hz}$, with an online artifact rejection threshold of $\pm 23 \mu \mathrm{V}$. The stimulus was presented in alternating polarity. To maximize the response to the speech formants, responses to the alternating polarities were subtracted, following conventions described previously (Aiken and Picton, 2008; Skoe and Kraus, 2010). To gauge the consistency of the response over the course of the recording, two subaverages of 3000 trials were created.

\section{Analyses}

Three independent measures were extracted from the ABR using custom routines coded in Matlab (Mathworks): Response Consistency, Speech Encoding, and Spontaneous Neural Activity. Response Consistency reflects the stability of the ABR over the recording session and is measured by correlating the two subaverages (Hornickel and Kraus, 2013). The closer the $r$ value is to 1 , the more repeatable the response is over the 20 min session. $r$ Values were Fisher transformed to $z$-scores for statistical analyses. Speech Encoding measures the strength with which the speech stimulus is represented in the ABR. The response was transformed into the frequency domain using fast Fourier analysis and the energy within the first formant frequency range $(264-656 \mathrm{~Hz})$ was averaged. The first formant carries important phonological information regarding the identity of the speech sound. Response Consistency and Speech Encoding were computed for the frequency-following region of the response, which for this stimulus falls between 11.4 and $40.6 \mathrm{~ms}$ (Krizman et al., 2012a). Spontaneous Neural Activity represents the magnitude of neural activity in the absence of a stimulus. It was calculated as the average root-mean-square magnitude of the response during the $15 \mathrm{~ms}$ prestimulus interval.

\section{Operational definitions}

\section{Auditory impoverishment}

We define "auditory impoverishment" as a reduction in auditory input relative to standard conditions. This reduction can arise either (1) because the sensory organs (inner ear) have been compromised by an insult, genetic mutation, disease, or normal aging and/or (2) because of limited acoustics or acoustic degradation within the environment. Environmental impoverishment comes in a variety of forms, ranging from complete sound isolation to a partial reduction in sound quality. Examples of auditory impoverishment include listening through a device that distorts the signal (e.g., cell phones), listening in reverberant or noisy conditions, hearing sounds that are less complex and/or socially less engaging, and hearing statistically fewer sounds overall (e.g., hearing fewer words per hour from caregivers). In this paper, we examine a specific type of auditory impoverishment, namely what happens when sensory organs are intact (and therefore hearing thresholds are normal) but the quality and quantity of a child's auditory input is limited as the result of reduced language-based social interactions and greater exposure 
Table 4. Group comparisons for the low- and high-MaternalEd groups on reading and cognitive measures ${ }^{a}$

\begin{tabular}{|c|c|c|c|c|c|}
\hline & Low-MaternalEd & High-MaternalEd & $F$ & $\begin{array}{l}\text { Significance } \\
\text { (two-tailed) }\end{array}$ & $\begin{array}{l}\text { Effect } \\
\text { size }\left(\eta^{2}\right)\end{array}$ \\
\hline IQ & Mean, 96.36; SD, 8.76 & Mean, 100.09; SD, 8.52 & 3.071 & 0.084 & 0.005 \\
\hline TOSWRF & Mean, 97.12; SD, 11.50 & Mean, 103.06; SD, 11.29 & 4.482 & $0.038^{*}$ & 0.065 \\
\hline TOWRE & Mean, 92.03; SD, 12.56 & Mean, 99.00; SD, 10.53 & 5.965 & $0.017^{*}$ & 0.085 \\
\hline Basic Reading & Mean, 95.21; SD, 7.39 & Mean, 100.97; SD, 9.23 & 7.830 & $0.007^{*}$ & 0.109 \\
\hline Spelling & Mean, 103.06; SD, 7.84 & Mean, 106.67; SD, 10.09 & 2.630 & 0.110 & 0.04 \\
\hline \multicolumn{6}{|l|}{ Working Memory } \\
\hline Numbers Reversed & Mean, 95.82; SD, 11.38 & Mean, 99.27; SD, 10.79 & 1.601 & 0.210 & 0.024 \\
\hline Auditory Working Memory & Mean, 100.55; SD, 9.71 & Mean, 106.76; SD, 10.47 & 6.244 & $0.015^{*}$ & 0.090 \\
\hline
\end{tabular}

${ }^{a}$ Tests are reported as age-normed standard scores with 100 corresponding to 50 th percentile.

${ }^{*} p<0.05$.

to unstructured, and behaviorally irrelevant, sounds, such as ambient noise.

\section{Auditory neural acuity}

We use the term "auditory neural acuity" to collectively refer to our three measures of brainstem function. We define "auditory neural acuity" as the nervous system's ability to resolve and reliably transmit fine-grained information about acoustic signals within the environment. By controlling for hearing thresholds, we have minimized the role of the cochlea-the peripheral, sensory organ of hearing - to isolate the neural component of hearing.

\section{Statistical analyses}

To test the primary hypothesis that auditory impoverishment, as operationalized here by maternal education, affects how auditory signals are encoded in the brain, the low- and high-MaternalEd groups were compared using a one-way ANOVA. One-way ANOVAs were also used to compare the low and high groups on each of the behavioral measures of IQ, reading, and working memory. For each comparison, $F$ and $p$ statistics are reported, along with $\eta^{2}$, the estimated effect size. Following Cohen's conventions (Cohen, 1988), an effect size between 0.01 and 0.059 is considered small, between 0.059 and 0.138 is medium, and $\geq 0.138$ is large.

In a follow-up analysis, we used regression techniques to examine the relationship among the neural and behavioral measures. First, using multiple linear regression models, we tested which combination, if any, of the behavioral measures predict brainstem function. Second, using binary logistic regression models, we examined how the behavioral and neural measures uniquely and collectively predict group membership. Through this binary logistic analysis, we aimed to test whether neural acuity is a unique predictor of maternal education that cannot be accounted for by reading or cognitive ability. Binary logistic regression is a variant of regression, in which the dependent variable is categorical (i.e., low- vs high-MaternalEd). After initially examining colinearity among the independent variables via Pearson's correlations, we selected a subset of neural and cognitive variables to include in the linear and binary logistic regression models with the goal of reducing multicolinearity (redundancy) within the models and improving the estimate of predictability for each independent variable entered into the model. For both types of regression, predictors were entered simultaneously into the model.

For the binary logistic analysis, we tested three models: the first included all three brainstem measures (three independent variables); the second model included representative measures of brainstem function, reading, and working memory (three independent variables); and the third model also factored in current exposure to English and hearing thresholds. We included the third model because the amount of exposure to the target language can influence both cognitive and language function (Dixon et al., 2012), and also because speech-evoked ABRs are sensitive to language experience (Krishnan et al., 2005; Krizman et al., 2012b). Hearing thresholds can likewise affect cognitive, reading, and brainstem measures (Hood, 1998; Moeller et al., 2007). Although the groups were matched with respect to both current language exposure and hearing thresholds, given that they can affect the neural and behavioral measures under consideration, we included them in the binary logistic regression analysis to further rule out their role in explaining our findings. All statistical analyses were performed in SPSS v21 (IBM).

\section{Results}

\section{Reading and cognitive measures}

Group differences emerged for all literacy-related tests except the spelling test. In addition, the low-MaternalEd group performed more poorly than the high-MaternalEd group on working memory ability but only on the more linguistically engaging subtest. See Table 4 for summary statistics.

\section{Neural measures}

For the low-MaternalEd group, ABRs were less stable over time (Response Consistency: $F_{(1,64)}=6.34, p=0.01, \eta^{2}=0.09$ ) compared with the high-MaternalEd group (Fig. 1). This instability was accompanied by weaker encoding of speech-specific information (Speech Encoding: $F_{(1,64)}=5.12, p=0.03, \eta^{2}=0.06$; Fig. $2)$. In addition, for the low-MaternalEd group, responses were noisier overall, as evidenced by greater activity during the silent intervals when no stimulus was being played (Spontaneous Neural Activity: $F_{(1,64)}=6.50, p=0.01, \eta^{2}=0.14$; Fig. 3).

\section{Correlations among measures}

Table 5 presents the correlations among the brainstem, reading, and working memory variables. Response Consistency was correlated with the other two brainstem variables. Yet, the amount of Spontaneous Neural Activity and the strength of Speech Encoding did not relate, suggesting that they reflect distinct neural mechanisms. For the subset of subjects for whom the exact years of maternal education was known $(n=46)$, we also examined relationships between this variable and each of the neural and behavioral measures (Table 5). This subanalysis revealed that more years of maternal education was associated with higher Response Consistency and more robust Speech Encoding (Table 5).

\section{Multiple linear regression analysis}

Using multiple linear regression analysis modeling, we tested whether reading ability and auditory working memory had a combined influence on brainstem function. Based on the outcomes of the one-way ANOVAs and the colinearity among variables (Table 5), we selected two independent variables (TOSWRF, Auditory Working Memory) and one dependent measure (Response Consistency) to include in the model. Response Consistency was selected as the representative brainstem variable because it was correlated with the two other measures of brainstem function but the other two measures were not interrelated, suggesting that Response Consistency may capture aspects 
A
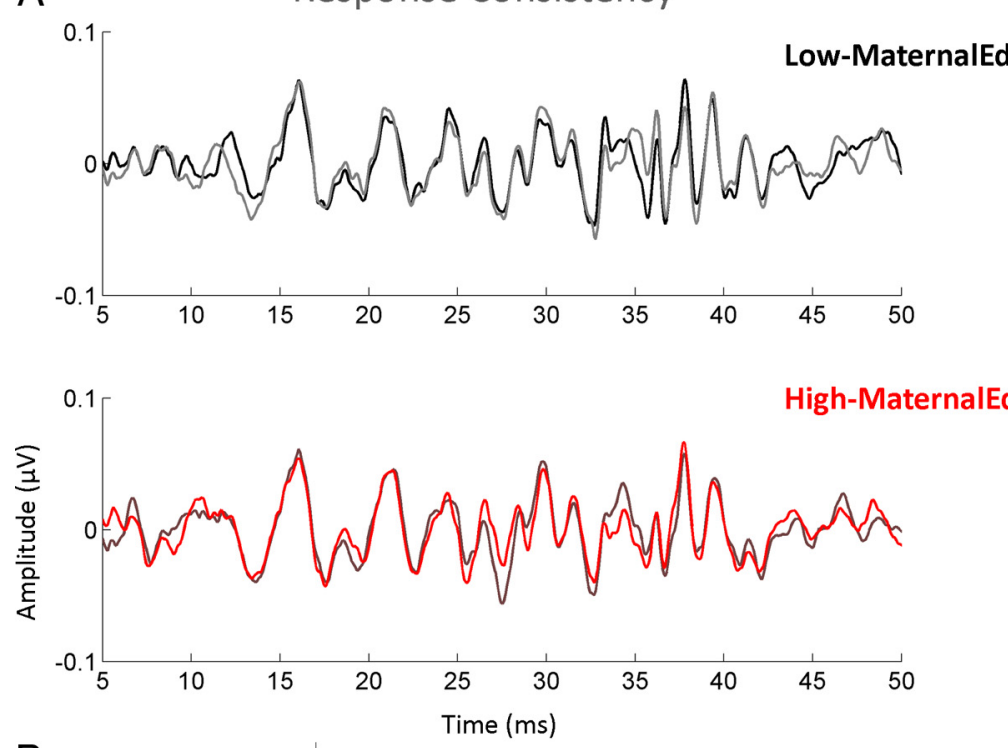

B

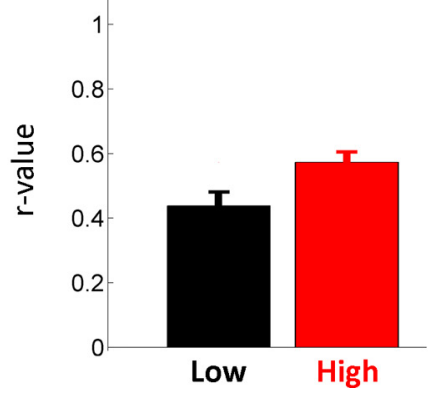

Figure 1. Adolescents with low maternal education (black) have less consistent auditory brain responses (ABRs) than adolescents with high maternal education (red). $\boldsymbol{A}$, For the low-MaternalEd group (top) and high-MaternalEd group (bottom), the ABR during the first half of the recording (black/red, respectively) is compared with the response during the second half of the recording (gray). For the high group, the two waveforms align more closely in morphology than for the low group $(p=0.01)$. $\boldsymbol{B}$, The average correlation ( $r$ value) between the first and second halves of the recording is 0.44 for the low group versus 0.57 for the high group $(r=1$, when the two halves are identical). Mean +1 SEM are plotted.

of the other two neural measures. TOSWRF was chosen as the primary measure of reading because it was correlated with the other measures of reading, but unlike the other reading measures (TOWRE, Basic Reading) it did not correlate with either measure of working memory (Digits Reversed, Auditory Working Memory). Auditory Working Memory was selected over Digits Reversed because the low- and high-MaternalEd groups did not differ statistically on the Digits Reversed measure, and the effect size was comparatively low. In addition, compared with the Numbers Reversed subtest, this Auditory Working Memory test has a higher receptive language requirement due to the open set nature of the test (Flanagan, 2001). By requiring greater manipulation of the input, this test may also require greater demands from the frontal executive function system (St Clair-Thompson, 2009).

The results of the regression indicated that reading and working memory were not significant predictors of brainstem function $\left(R^{2}=0.001, F_{(2,65)}=0.038, p=0.963\right)$. Adding in maternal education group, as a binary predictor variable, the combined model predicted $11 \%$ of the variance of brainstem function $\left(R^{2}=\right.$ $\left.0.110, F_{(3,65)}=2.546, p=0.064\right)$, with maternal education being the only significant individual predictor (standardized regression coefficient $\mathrm{B}=0.159, t=2.748, p=0.008$ ).

\section{Binary logistic regression}

To examine how the neural and behavioral measures combined to predict group membership, we used binary logistic regression modeling. The results of the three models are reported in Table 6. All three models produced statistically significant results. Model 1, which included all brainstem variables, predicted $\sim 65 \%$ of the cases. In Model 2, when factoring in the representative reading, working memory, and brainstem variables, the prediction increased to $75.8 \%$ correct, with $\mathrm{Re}$ sponse Consistency and Auditory Working Memory making unique, independent contributions to the model (both $p<$ 0.05 ) and with reading ability (TOSWRF) adding to the predictive power of the model without carrying significant predictive power on its own $(p=0.08)$. In Model 3, we confirmed that neither peripheral hearing levels nor current exposure to English contributed to the model.

\section{Discussion}

We examined the link between SES and adolescent brain function in a normalhearing population using maternal education as a proxy for SES (Bradley and Corwyn, 2002). In addition to finding that low maternal education is associated with poorer performance on tests of reading and working memory, we find that ABRs from the low-maternalEd group were noisier, more variable, and represented the input signal more weakly. Because low maternal education increases the risk for auditory impoverishment (Evans, 2004), poorer auditory neural acuity in the low maternal education group is argued to arise from impoverished early auditory experiences, which, as our findings suggest, become "embedded" in a person's biology (Hertzman and Boyce, 2010) to negatively shape the nervous system's automatic response to sound.

\section{The impact of small differences in SES}

We studied a cohort of adolescents who likely have had different auditory experiences, as operationalized by differences in maternal education (Bradley and Corwyn, 2002), but were matched in age, sex, hearing, ethnicity, and the schools they attended. This homogeneity of our sample permitted more strict evaluation of the link between maternal education, a component of SES, and brain function while controlling for many confounding variables (D’Angiulli et al., 2008; Helvik et al., 2009; Pungello et al., 2009). By recruiting from the Chicago Public School system, a "majority-minority" district that serves primarily low-income populations, most, if not all, of the participants in our study could be considered socioeconomically disadvantaged (Chicago Public Schools, 2013), with our lower and higher groups representing gradients on the lower end of the socioeconomic spectrum. As such, our study is capturing a relatively narrow slice of the SES spectrum. Nevertheless, we observe striking differences in auditory neural acuity, reading ability, and 
working memory based on differences in maternal education within this lower end.

It is unclear at this point whether our findings generalize to other populations, or what the full ramifications of these neural differences might be. But we believe that this study makes an important first step by establishing that auditory impoverishment and auditory neural acuity are linked. In addition, given that our two groups had similar demographics, our findings highlight the potential for small differences in early auditory experiences to cascade into larger neural and cognitive gaps over time (Brooks-Gunn and Duncan, 1997; Haskins and Rouse, 2005; Fryer and Levitt, 2006; Stevens et al., 2009). Based on the outcomes of this study, we plan to undertake a larger research program that will delve more deeply into understanding the transient and longstanding effects of early socioeconomic adversity on auditory neural activity, cognitive function, and social mobility across different ages, ethnicities, and geographies.

\section{Normal auditory processing depends on the quality and quantity of environmental stimulation}

We screened for conductive and sensorineural hearing loss to ensure that all participants had normal hearing thresholds at the time of testing and that audibility did not differ between groups. This is an important experimental control given that ear infections and hearing loss are more common in underprivileged populations (Paradise et al., 1997; Olatoke et al., 2008; Helvik et al., 2009; Siddartha et al., 2012). By controlling for hearing thresholds, we are in a stronger position to argue that the differences in auditory neural acuity between the low and high groups reflect differences in environmental stimulation throughout childhood. Children from lower-SES backgrounds are exposed to less complex and linguistically rich input in addition to hearing fewer words per hour from their caregivers (Hart and Risley, 1995; Sheridan et al., 2012; Cartmill et al., 2013). Low-SES children also watch more television than their higher-SES peers, which may increase their passive exposure to sound (Evans, 2004), but further limits opportunities to interact with a diverse, as well as an emotionally and socially engaging, soundscape (Kuhl et al., 2003; Sanes and Woolley, 2011). In addition to being underexposed to linguistically stimulating environments, socioeconomically disadvantaged children face greater exposure to noise pollution (Fidell, 1978; Evans and Kantrowitz, 2002; Kohlhuber et al., 2006), further compromising the quality of the auditory input by increasing the amount of unstructured, irrelevant input. Thus, while their aggregate auditory input might not be diminished, the complexity and clarity of the auditory input and how they interact with sound is atypical. This combination of environmental factors, we argue, leads to diminare plotted for both groups.

\section{Speech Encoding}

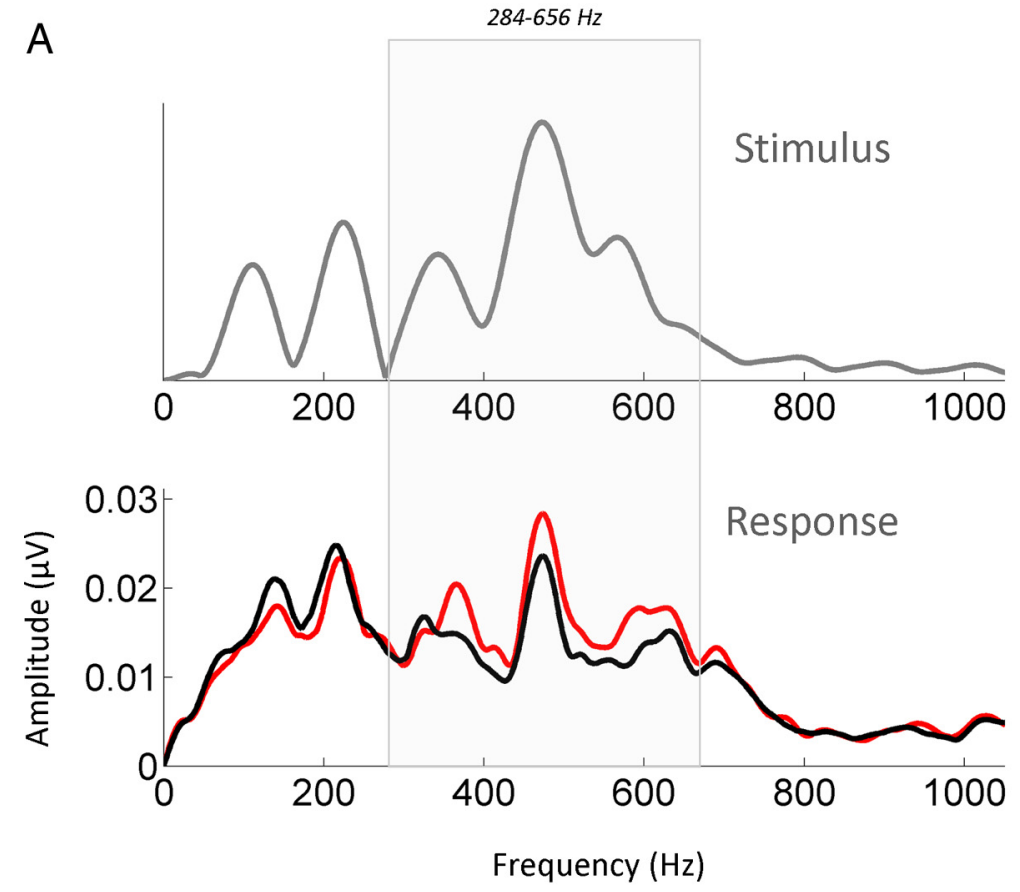

Low-MaternalEd

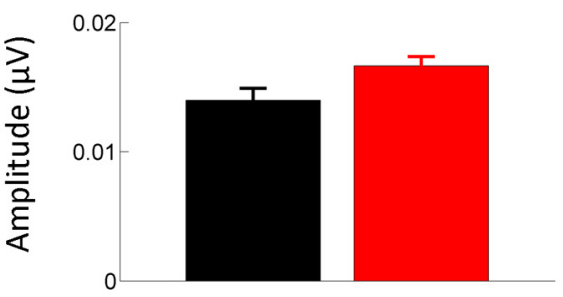

High-MaternalEd

Figure 2. Adolescents with lower maternal education (black) have smaller auditory brainstem responses (ABRs) to the speech stimulus than adolescents with higher maternal education (red). $\boldsymbol{A}$, The speech frequency spectrum is plotted. The band of energy groups. For the response to the first formant, the average energy is reduced in the low-MaternalEd group compared with the high-MaternalEd group $(p=0.03)$, suggesting that the speech stimulus is encoded less robustly in the low group. Mean +1 SEM

ished neural encoding of auditory signals in children with low maternal education.

\section{Noise in, noise out: noisy auditory environment increases neural noise}

Within urban populations, income and amount of noise exposure are known to be correlated (Fidell, 1978), with the average noise exposure being $\sim 15 \mathrm{~dB}$ SPL higher in households earning $\sim \$ 35,000 /$ year compared with those earning $\$ 70,000 /$ year $(70 \mathrm{~dB}$ vs $55 \mathrm{~dB}$ SPL, income adjusted for inflation; Fidell, 1978). Additionally, although ambient noise levels differ by neighborhood, socioeconomic gradients within a neighborhood enable wealthier residents to afford higher-quality housing that dampens ambient noise (Fyhri and Klæboe, 2006). Therefore, even within our population, there may be inequalities in noise exposure. While ambient noise levels may be too low to decrease audibility, chronic low-level noise exposure has been shown to decrease reading and cognitive performance (Cohen et al., 1973; Bronzaft and McCarthy, 1975; Hygge et al., 2002), change how children discriminate and attend to auditory stimuli (Cohen et al., 1973; 
A

\section{Spontaneous Neural Activity}
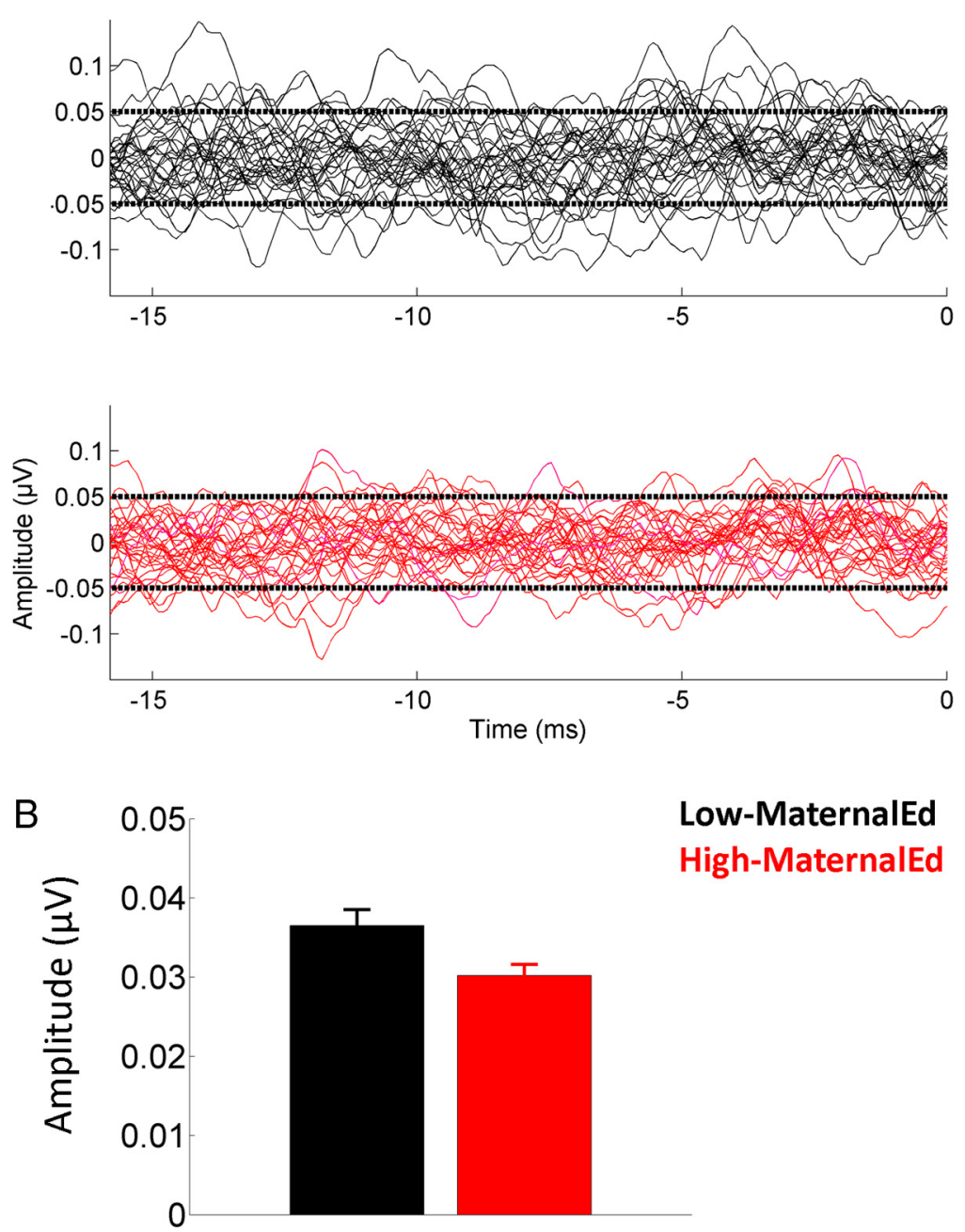

Figure 3. Adolescents with lower maternal education (black) have more spontaneous neural activity than those with higher maternal education (red). $\boldsymbol{A}$, Neural activity is plotted for each participant in the low-MaternalEd (top) and high-MaternalEd (bottom) groups during the $15 \mathrm{~ms}$ of silence preceding each stimulus presentation. Time 0 refers to when the stimulus starts playing. $\boldsymbol{B}$, The average energy is greater in the low group compared with the high group $(p=0.01)$. Increased energy during the absence of auditory input is argued to be indicative of greater neural noise.

Bronzaft and McCarthy, 1975; Evans et al., 1995), and leave the auditory system more vulnerable in the long term (Evans and Kantrowitz, 2002; Kujawa and Liberman, 2006). As has been shown in laboratory animals, chronic noise exposure can also alter neural function by reducing the brain's sensitivity to sound (Zhou and Merzenich, 2012), delaying auditory development (Chang and Merzenich, 2003), accelerating age-related hearing loss (Kujawa and Liberman, 2006), and increasing neural noise, the spontaneous firing of neurons in the absence of stimulation (Costalupes et al., 1984; Noreña and Eggermont, 2003; Seki and Eggermont, 2003; Pienkowski and Eggermont, 2012; Mulders and Robertson, 2013).

Consistent with the idea that noisy auditory environments increase neural noise, we found that adolescents from the lowMaternalEd group, compared with those from the high group, have increased neural activity in the absence of sound input. Neural models indicate that when the input to a neuron is noisier, firing rate becomes more variable, ultimately limiting the amount of sensory information that can be transmitted (Stein et al., 2005). Additionally, when input to the auditory system is not coherent from one instance of a sound to the next, signal transmission is less effective, interrupting the ability to form a stable representation of the auditory world (Ahissar, 2007; Centanni et al., 2013; Hornickel and Kraus, 2013). We have observed this increase in neural noise and decrease in response consistency by probing the auditory system; however, we believe it is reflective of increased spontaneous activity throughout the brain. We conclude that increased neural variability and noise observed in the low-maternalEd group reflect an inefficient sensory system in which the ability to translate an external stimulus into a meaningful electrical signal is compromised (Centanni et al., 2013; Hornickel and Kraus, 2013). This noise and instability in the encoding of sensory signals may in turn affect higher-level functions that depend on that signal (Fox et al., 2010).

\section{Auditory impoverishment may lead to the decoupling of sensory and cognitive functions}

Our data advance the theory that auditory experiences help to forge the "scaffolding" that binds sensory and cognitive information in the brain (Conway et al., 2009; Kraus et al., 2012; Krizman et al., 2012b). We posit that this biological scaffolding, once formed, can be traversed in both "directions," allowing for stable transmission of both bottom-up and top-down signals and the interlocking of these signals. Yet, if auditory impoverishment occurs early in life, this scaffolding may never fully form, or its neuroanatomical infrastructure may be intact but weaker, altering the typical relationships between sensory and cognitive functions (Sak and Ruben, 1981; Sininger et al., 1999; Kral and Eggermont, 2007; Conway et al., 2009). Although both sensory and cognitive systems were found to be linked to maternal education in our study, sensory and cognitive variables were uncorrelated. This is in contrast to other work, primarily from populations with average to high SES backgrounds, in which correlations between sensory and cognitive functions have been observed (Hornickel et al., 2009; Kraus et al., 2012). Although we leave open the possibility that our behavioral tests lack the sensitivity to illuminate weak correlations between sensory and cognitive abilities if they did exist (Stevens et al., 2009) and/or that the spread of SES is too narrow to see such relationships, the absence of a relationship could alternatively indicate that sensory and cognitive systems have not synched up, and that the normal processes that lead to a symbiotic tethering of sensory and cognitive systems have been compromised. We theorize that when this scaffolding is absent or malformed it further weakens the already deficient sensory and/or cognitive systems, such that sensory systems cannot benefit from top-down cognitive processes that refine how incoming sounds are pro- 
Table 5. Correlations among brainstem, cognitive, and years of maternal education variables ${ }^{a}$

\begin{tabular}{|c|c|c|c|c|c|c|c|c|c|c|c|}
\hline & $\begin{array}{l}\text { Response } \\
\text { Consistency }\end{array}$ & $\begin{array}{l}\text { Speech } \\
\text { Encoding }\end{array}$ & $\begin{array}{l}\text { Spontaneous } \\
\text { Activity }\end{array}$ & IQ & TOSWRF & TOWRE & $\begin{array}{l}\text { Basic } \\
\text { Reading }\end{array}$ & Spelling & $\begin{array}{l}\text { Digits } \\
\text { Reversed }\end{array}$ & $\begin{array}{l}\text { Auditory } \\
\text { Working } \\
\text { Memory }\end{array}$ & $\begin{array}{l}\text { Years of maternal } \\
\text { education }(n=46)\end{array}$ \\
\hline Response Consistency & & $0.718^{* *}$ & $-0.445^{* *}$ & 0.069 & 0.009 & 0.107 & 0.071 & 0.153 & 0.127 & -0.031 & $0.430^{* *}$ \\
\hline Speech Encoding & $0.718^{* *}$ & & -0.093 & -0.051 & -0.003 & 0.108 & 0.011 & 0.001 & 0.154 & 0.022 & $0.336^{*}$ \\
\hline Spontaneous Activity & $-0.445^{* *}$ & -0.093 & & -0.046 & -0.119 & 0.045 & -0.075 & -0.175 & -0.073 & 0.012 & -0.24 \\
\hline IQ & 0.069 & -0.051 & -0.046 & & 0.219 & $0.346^{* *}$ & $0.512^{* *}$ & $0.399 * *$ & $0.293^{*}$ & $0.374^{* *}$ & -0.053 \\
\hline TOSWRF & 0.009 & -0.003 & -0.119 & 0.219 & & $0.432^{* *}$ & $0.380 * *$ & $0.433^{* *}$ & 0.006 & 0.156 & 0.022 \\
\hline TOWRE & 0.107 & 0.108 & 0.045 & $0.346^{* *}$ & $0.432^{* *}$ & & $0.699 * *$ & $0.641^{* *}$ & 0.151 & $0.265^{*}$ & 0.047 \\
\hline Basic Reading & 0.071 & 0.011 & -0.075 & $0.512^{* *}$ & $0.380^{* *}$ & $0.699 * *$ & & $0.743^{* *}$ & $0.248^{*}$ & $0.399^{* *}$ & 0.133 \\
\hline Spelling & 0.153 & 0.001 & -0.175 & $0.399^{* *}$ & $0.433^{* *}$ & $0.641^{* *}$ & $0.743^{* *}$ & & 0.155 & $0.350^{* *}$ & 0.063 \\
\hline Digits Reversed & 0.127 & 0.154 & -0.073 & $0.293^{*}$ & 0.006 & 0.151 & $0.248^{*}$ & 0.155 & & $0.608^{* *}$ & 0.026 \\
\hline Auditory Working Memory & -0.031 & 0.022 & 0.012 & $0.374^{* *}$ & 0.156 & $0.265^{*}$ & $0.399 * *$ & $0.350^{* *}$ & $0.608^{* *}$ & & -0.074 \\
\hline Years of maternal education & $0.430^{* *}$ & $0.336^{*}$ & -0.24 & -0.053 & 0.022 & 0.047 & 0.133 & 0.063 & 0.026 & -0.074 & \\
\hline
\end{tabular}

${ }^{a}$ Comparisons with years of maternal education was performed on a subset of the group $(n=46)$. All other comparisons included the full dataset $(n=66)$.

${ }^{*} p<0.05 ;{ }^{* *} p<0.01$.

Table 6. Binary logistic regression

\begin{tabular}{|c|c|c|c|c|c|c|}
\hline & \multirow[b]{2}{*}{ Independent variable(s) } & \multirow[b]{2}{*}{ Standardized regression coefficients } & \multirow[b]{2}{*}{ Overall model, $\chi^{2}$} & \multicolumn{3}{|c|}{ Correct classification (\%) } \\
\hline & & & & $\begin{array}{l}\text { Low- } \\
\text { Mater- } \\
\text { nalEd }\end{array}$ & $\begin{array}{l}\text { High- } \\
\text { Mater- } \\
\text { nalEd }\end{array}$ & Total \\
\hline \multirow[t]{4}{*}{ Model $1^{a}$} & Response Consistency & $B=-0.130, \mathrm{SE}=2.085, p=0.950$ & & & & \\
\hline & Speech Encoding & $B=121.576, \mathrm{SE}=88.739, p=0.171$ & & & & \\
\hline & Spontaneous Activity & $B=-66.152, \mathrm{SE}=34.298, p=0.054$ & & & & \\
\hline & Combined & & $\chi_{(3)}^{2}=10.905, p=0.012$ & 60.6 & 69.7 & 65.2 \\
\hline \multirow[t]{4}{*}{ Model $2^{a}$} & Brainstem*: Response Consistency & $B=3.553, \mathrm{SE}=1.409, p=0.019$ & & & & \\
\hline & Reading: Test of Sight Word Reading & $B=0.047, \mathrm{SE}=0.026, p=0.067$ & & & & \\
\hline & Working memory*: Auditory Working Memory & $B=0.070, \mathrm{SE}=0.031, p=0.022$ & & & & \\
\hline & Combined & & $\chi_{(3)}^{2}=17.118, p=0.001$ & 78.8 & 72.7 & 75.8 \\
\hline \multirow[t]{5}{*}{ Model $3^{a}$} & Brainstem*: Response Consistency & $B=3.683, \mathrm{SE}=1.464, p=0.012$ & & & & \\
\hline & Reading : Test of Sight Word Reading & $B=0.047, \mathrm{SE}=0.027, p=0.082$ & & & & \\
\hline & Working memory*: Auditory Working Memory & $B=0.069, \mathrm{SE}=0.032, p=0.029$ & & & & \\
\hline & Hearing threshold: pure tone averages for left and right ear & $B=-0.034, \mathrm{SE}=0.072, p=0.966$ & & & & \\
\hline & $\begin{array}{l}\text { English exposure: current exposure to English } \\
\text { Combined }\end{array}$ & $B=0.018, \mathrm{SE}=0.015, p=0.225$ & $\chi_{(5)}^{2}=18.926, p=0.002$ & 80 & 75 & 77.4 \\
\hline
\end{tabular}

${ }^{a}$ Dependent variable: maternal education category. $\sim p<0.1 ;{ }^{*} p<0.05$

cessed, and cognitive processes cannot benefit from that refined sensory input.

By suggesting that alterations to the prefrontal cortex and other higher-order systems may lead to and subsequently reinforce a breakdown in sensory-cognitive feedback, this sensorycognitive scaffolding theory provides new mechanistic insight into the previously described differences in higher-order functions associated with SES (Noble et al., 2007). This breakdown, coupled with reduced auditory acuity, may then translate into disparities in how auditory information is processed in both active (D'Angiulli et al., 2008; Stevens et al., 2009) and passive (current study) listening contexts.

\section{Auditory function and social mobility}

Intergenerational social mobility in the United States is among the lowest of the developed economies (Beller and Hout, 2006): children born into poverty are unlikely to move out of poverty. While there are myriad reasons for this low social mobility, we argue that reductions in fundamental auditory neural function may play a part. Because auditory disorders run in families (e.g., Maziade et al., 2000), auditory neural acuity may be transmitted from one generation to the next by genetic mechanisms. Yet, our study emphasizes that auditory neural acuity may also reflect the auditory environment that is shared between mother and child. Moreover, given that the heritability of some traits is altered under suboptimal environmental conditions (Turkheimer et al., 2003; Jukes and Grigorenko, 2010), this supports the possibility that environmental factors play an especially prominent role when the auditory environment is impoverished.

What can be done to break this intergenerational negative feedback loop and reverse the effects of poor environmental conditions on auditory neural acuity? By documenting how socioeconomic factors impede sensory and cognitive function, it may be possible to use that information to develop appropriate intervention strategies that target specific neurobiological processes. Music education may be one promising remediation strategy (Fitzpatrick, 2006; Kraus and Chandrasekaran, 2010; Patel, 2011). Classroom-based auditory enrichment, in the form of assistive listening devices, may also be a successful option. In children with dyslexia, this type of remediation has produced more stable ABRs (Hornickel et al., 2012), a characteristic of the response that was compromised in our group with lower maternal education and which has been previously shown to be a factor for reading ability (Centanni et al., 2013; Hornickel and Kraus, 2013). There is accumulating evidence that the auditory brainstem remains malleable throughout life (Carcagno and Plack, 2011; Hornickel et al., 2012; Song et al., 2012; Anderson et al., 2013a; Strait et al., 2013), further supporting the prospect that acuity can be improved with appropriate intervention strategies. 
Interventions that foster quality parent-child interactions at home also offer great promise in bolstering the neurobiological systems compromised by socioeconomic conditions (Neville et al., 2013). Optimistically, it may just be a matter of finding the right kind of remediation, knowing when such training is most effective, and delivering it in a way that is cost-effective and appropriate for use in a variety of classroom and home settings (Moore, 2002; Als et al., 2004; Raizada and Kishiyama, 2010). However, this is not to downplay the necessity to improve the social and educational systems that led to disparities in maternal education in the first place. Our findings suggest that even small gains in maternal education - the difference between a high school degree and a few college courses - could make a difference in a child's sensory and cognitive development and break the intergenerational negative-feedback loop that affects social mobility (Brooks-Gunn and Duncan, 1997).

\section{References}

Ahissar M (2007) Dyslexia and the anchoring-deficit hypothesis. Trends Cogn Sci 11:458-465. CrossRef Medline

Aiken SJ, Picton TW (2008) Envelope and spectral frequency-following responses to vowel sounds. Hear Res 245:35-47. CrossRef Medline

Als H, Duffy FH, McAnulty GB, Rivkin MJ, Vajapeyam S, Mulkern RV, Warfield SK, Huppi PS, Butler SC, Conneman N, Fischer C, Eichenwald EC (2004) Early experience alters brain function and structure. Pediatrics 113:846-857. CrossRef Medline

Anderson S, White-Schwoch T, Parbery-Clark A, Kraus N (2013a) Reversal of age-related neural timing delays with training. Proc Natl Acad Sci U S A 110:4357-4362. CrossRef Medline

Anderson S, Parbery-Clark A, White-Schwoch T, Drehobl S, Kraus N (2013b) Effects of hearing loss on the subcortical representation of speech cues. J Acoust Soc Am 133:3030-3038. CrossRef Medline

Banai K, Hornickel J, Skoe E, Nicol T, Zecker S, Kraus N (2009) Reading and subcortical auditory function. Cereb Cortex 19:2699-2707. CrossRef Medline

Beller E, Hout M (2006) Intergenerational social mobility: the United States in comparative perspective. Future Child 16:19-36. Medline

Blakemore C, Cooper GF (1970) Development of the brain depends on the visual environment. Nature 228:477-478. CrossRef Medline

Bradley RH, Corwyn RF (2002) Socioeconomic status and child development. Annu Rev Psychol 53:371-399. CrossRef Medline

Bronzaft AL, McCarthy DP (1975) The effect of elevated train noise on reading ability. Environ Behav 7:517-527. CrossRef

Brooks-Gunn J, Duncan GJ (1997) The effects of poverty on children. Future Child 7:55-71. CrossRef Medline

Brooks-Gunn J, Klebanov PK, Duncan GJ (1996) Ethnic differences in children's intelligence test scores: role of economic deprivation, home environment, and maternal characteristics. Child Dev 67:396-408. CrossRef Medline

Carcagno S, Plack CJ (2011) Subcortical plasticity following perceptual learning in a pitch discrimination task. J Assoc Res Otolaryngol 12:89100. CrossRef Medline

Cartmill EA, Armstrong BF 3rd, Gleitman LR, Goldin-Meadow S, Medina TN, Trueswell JC (2013) Quality of early parent input predicts child vocabulary 3 years later. Proc Natl Acad Sci U S A 110:11278-11283. CrossRef Medline

Centanni TM, Booker AB, Sloan AM, Chen F, Maher BJ, Carraway RS, Khodaparast N, Rennaker R, Loturco JJ, Kilgard MP (2013) Knockdown of the dyslexia-associated gene Kiaa0319 impairs temporal responses to speech stimuli in rat primary auditory cortex. Cereb Cortex. Advance online publication. Retrieved September 18, 2013. doi:10.1093/cercor/ bht028. CrossRef Medline

Chang EF, Merzenich MM (2003) Environmental noise retards auditory cortical development. Science 300:498-502. CrossRef Medline

Cohen J (1988) Statistical power analysis for the behavioral sciences. Hillsdale, NJ: L. Erlbaum Associates.

Cohen S, Glass DC, Singer JE (1973) Apartment noise, auditory discrimination, and reading ability in children. J Exp Soc Psychol 9:407-422. CrossRef

Conway CM, Pisoni DB, Kronenberger WG (2009) The importance of sound for cognitive sequencing abilities: the auditory scaffolding hypothesis. Curr Dir Psychol Sci 18:275-279. CrossRef Medline

Costalupes JA, Young ED, Gibson DJ (1984) Effects of continuous noise backgrounds on rate response of auditory nerve fibers in cat. J Neurophysiol 51:1326-1344. Medline

Chicago Public Schools (2013) Chicago Public School District: facts and stats. http://www.cps.edu/about_cps/at-a-glance/pages/stats_and_facts.aspx.

D'Angiulli A, Herdman A, Stapells D, Hertzman C (2008) Children's eventrelated potentials of auditory selective attention vary with their socioeconomic status. Neuropsychology 22:293-300. CrossRef Medline

Dixon LQ, Wu S, Daraghmeh A (2012) Profiles in bilingualism: factors influencing kindergartners' language proficiency. Early Child Ed J 40:2534. CrossRef

Eggermont JJ, Ponton CW, Don M, Waring MD, Kwong B (1997) Maturational delays in cortical evoked potentials in cochlear implant users. Acta Otolaryngol 117:161-163. CrossRef Medline

Evans GW (2004) The environment of childhood poverty. Am Psychol 59: 77-92. CrossRef Medline

Evans GW, Kantrowitz E (2002) Socioeconomic status and health: the potential role of environmental risk exposure. Annu Rev Public Health 23: 303-331. CrossRef Medline

Evans GW, Schamberg MA (2009) Childhood poverty, chronic stress, and adult working memory. Proc Natl Acad Sci U S A 106:6545-6549. CrossRef Medline

Evans GW, Hygge S, Bullinger M (1995) Chronic noise and psychological stress. Psychol Sci 6:333-338. CrossRef

Fidell S (1978) Nationwide urban noise survey. J Acoust Soc Am 64:198215. CrossRef Medline

Fitzpatrick KR (2006) The effect of instrumental music participation and socioeconomic status on Ohio fourth-, sixth-, and ninth-grade proficiency test performance. J Res Music Ed 54:73-84. CrossRef

Flanagan D (2001) Comparative features of the WJ III ${ }^{\circledR}$ tests of cognitive abilities and the Wechsler intelligence scales. Rolling Meadows, IL: The Riverside Publishing Company.

Fox SE, Levitt P, Nelson CA 3rd (2010) How the timing and quality of early experiences influence the development of brain architecture. Child Dev 81:28-40. CrossRef Medline

Fryer RG, Levitt SD (2006) The black-white test score gap through third grade. Am Law Econ Rev 8:249-281. CrossRef

Fyhri A, Klæboe R (2006) Direct, indirect influences of income on road traffic noise annoyance. J Environ Psychol 26:27-37. CrossRef

Hackman DA, Farah MJ (2009) Socioeconomic status and the developing brain. Trends Cogn Sci 13:65-73. CrossRef Medline

Hackman DA, Farah MJ, Meaney MJ (2010) Socioeconomic status and the brain: mechanistic insights from human and animal research. Nat Rev Neurosci 11:651-659. CrossRef Medline

Hanson JL, Chandra A, Wolfe BL, Pollak SD (2011) Association between income and the hippocampus. PLoS One 6:e18712. CrossRef Medline

Hart B, Risley TR (1995) Meaningful differences in the everyday experience of young American children. Baltimore: P.H. Brookes.

Haskins R, Rouse CE (2005) Closing achievement gaps. Washington, DC: Brookings Institution.

Hauber ME, Woolley SM, Cassey P, Theunissen FE (2013) Experience dependence of neural responses to different classes of male songs in the primary auditory forebrain of female songbirds. Behav Brain Res 243: 184-190. CrossRef Medline

Helvik AS, Krokstad S, Tambs K (2009) Socioeconomic inequalities in hearing loss in a healthy population sample: The HUNT study. Am J Public Health 99:1376-1378. CrossRef Medline

Hertzman C, Boyce T (2010) How experience gets under the skin to create gradients in developmental health. Annu Rev Public Health 31:329-347, $3 \mathrm{p}$ following 347. CrossRef Medline

Hoff E, Laursen B, Bridges K (2012) Measurement and model building in studying the influence of socioeconomic status on child development. In: The Cambridge handbook of environment in human development, pp 590-606. Cambridge: Cambridge UP.

Hood LJ (1998) Clinical applications of the auditory brainstem response. San Diego: Singular Publishing Group.

Hornickel J, Kraus N (2013) Unstable representation of sound: a biological marker of dyslexia. J Neurosci 33:3500-3504. CrossRef Medline

Hornickel J, Skoe E, Nicol T, Zecker S, Kraus N (2009) Subcortical differen- 
tiation of stop consonants relates to reading and speech-in-noise perception. Proc Natl Acad Sci U S A 106:13022-13027. CrossRef Medline

Hornickel J, Zecker SG, Bradlow AR, Kraus N (2012) Assistive listening devices drive neuroplasticity in children with dyslexia. Proc Natl Acad Sci U S A 109:16731-16736. CrossRef Medline

Hyde PS, Knudsen EI (2002) The optic tectum controls visually guided adaptive plasticity in the owl's auditory space map. Nature 415:73-76. CrossRef Medline

Hygge S, Evans GW, Bullinger M (2002) A prospective study of some effects of aircraft noise on cognitive performance in schoolchildren. Psychol Sci 13:469-474. CrossRef Medline

Jednoróg K, Altarelli I, Monzalvo K, Fluss J, Dubois J, Billard C, DehaeneLambertz G, Ramus F (2012) The influence of socioeconomic status on children's brain structure. PLoS One 7:e42486. CrossRef Medline

Jukes MC, Grigorenko EL (2010) Assessment of cognitive abilities in multiethnic countries: the case of the Wolof and Mandinka in the Gambia. Br J Educ Psychol 80:77-97. CrossRef Medline

Kishiyama MM, Boyce WT, Jimenez AM, Perry LM, Knight RT (2009) Socioeconomic disparities affect prefrontal function in children. J Cogn Neurosci 21:1106-1115. CrossRef Medline

Kohlhuber M, Mielck A, Weiland SK, Bolte G (2006) Social inequality in perceived environmental exposures in relation to housing conditions in Germany. Environ Res 101:246-255. CrossRef Medline

Kral A, Eggermont JJ (2007) What's to lose and what's to learn: development under auditory deprivation, cochlear implants and limits of cortical plasticity. Brain Res Rev 56:259-269. CrossRef Medline

Kraus N, Chandrasekaran B (2010) Music training for the development of auditory skills. Nat Rev Neurosci 11:599-605. CrossRef Medline

Kraus N, Strait DL, Parbery-Clark A (2012) Cognitive factors shape brain networks for auditory skills: spotlight on auditory working memory. Ann N Y Acad Sci 1252:100-107. CrossRef Medline

Krishnan A, Xu Y, Gandour J, Cariani P (2005) Encoding of pitch in the human brainstem is sensitive to language experience. Brain Res Cogn Brain Res 25:161-168. CrossRef Medline

Krizman J, Skoe E, Kraus N (2012a) Sex differences in auditory subcortical function. Clin Neurophysiol 123:590-597. CrossRef Medline

Krizman J, Marian V, Shook A, Skoe E, Kraus N (2012b) Subcortical encoding of sound is enhanced in bilinguals and relates to executive function advantages. Proc Natl Acad Sci U S A 109:7877-7881. CrossRef Medline

Kuhl PK, Tsao FM, Liu HM (2003) Foreign-language experience in infancy: effects of short-term exposure and social interaction on phonetic learning. Proc Natl Acad Sci U S A 100:9096-9101. CrossRef Medline

Kujawa SG, Liberman MC (2006) Acceleration of age-related hearing loss by early noise exposure: evidence of a misspent youth. J Neurosci 26: 2115-2123. CrossRef Medline

Lipina SJ, Posner MI (2012) The impact of poverty on the development of brain networks. Front Hum Neurosci 6:238. CrossRef Medline

Maddieson I (1984) Patterns of sounds. Cambridge: Cambridge UP.

Marian V, Blumenfeld HK, Kaushanskaya M (2007) The Language Experience and Proficiency Questionnaire (LEAP-Q): assessing language profiles in bilinguals and multilinguals. J Speech Lang Hear Res 50:940-967. CrossRef Medline

Marshall PJ, Reeb BC, Fox NA, Nelson CA 3rd, Zeanah CH (2008) Effects of early intervention on EEG power and coherence in previously institutionalized children in Romania. Dev Psychopathol 20:861-880. CrossRef Medline

Maziade M, Mérette C, Cayer M, Roy MA, Szatmari P, Côté R, Thivierge J (2000) Prolongation of brainstem auditory-evoked responses in autistic probands and their unaffected relatives. Arch Gen Psychiatry 57:10771083. CrossRef Medline

Moeller MP, Tomblin JB, Yoshinaga-Itano C, Connor CM, Jerger S (2007) Current state of knowledge: language and literacy of children with hearing impairment. Ear Hear 28:740-753. Medline

Moore DR (2002) Auditory development and the role of experience. Br Med Bull 63:171-181. CrossRef Medline

Mulders WH, Robertson D (2013) Development of hyperactivity after acoustic trauma in the guinea pig inferior colliculus. Hear Res 298:104108. CrossRef Medline

Neville HJ, Stevens C, Pakulak E, Bell TA, Fanning J, Klein S, Isbell E (2013) Family-based training program improves brain function, cognition, and behavior in lower socioeconomic status preschoolers. Proc Natl Acad Sci U S A 110:12138-12143. CrossRef Medline
Noble KG, Norman MF, Farah MJ (2005) Neurocognitive correlates of socioeconomic status in kindergarten children. Dev Sci 8:74-87. CrossRef Medline

Noble KG, Wolmetz ME, Ochs LG, Farah MJ, McCandliss BD (2006) Brainbehavior relationships in reading acquisition are modulated by socioeconomic factors. Dev Sci 9:642-654. Medline

Noble KG, McCandliss BD, Farah MJ (2007) Socioeconomic gradients predict individual differences in neurocognitive abilities. Dev Sci 10:464480. CrossRef Medline

Noble KG, Houston SM, Kan E, Sowell ER (2012) Neural correlates of socioeconomic status in the developing human brain. Dev Sci 15:516-527. CrossRef Medline

Noreña AJ, Eggermont JJ (2003) Changes in spontaneous neural activity immediately after an acoustic trauma: implications for neural correlates of tinnitus. Hear Res 183:137-153. CrossRef Medline

Olatoke F, Ologe FE, Nwawolo CC, Saka MJ (2008) The prevalence of hearing loss among schoolchildren with chronic suppurative otitis media in Nigeria, and its effect on academic performance. Ear Nose Throat J 87: E19. Medline

Otero GA (1997) Poverty, cultural disadvantage and brain development: a study of pre-school children in Mexico. Electroencephalogr Clin Neurophysiol 102:512-516. CrossRef Medline

Paradise JL, Rockette HE, Colborn DK, Bernard BS, Smith CG, Kurs-Lasky M, Janosky JE (1997) Otitis media in 2253 Pittsburgh-area infants: prevalence and risk factors during the first two years of life. Pediatrics 99:318 333. CrossRef Medline

Patel AD (2011) Why would musical training benefit the neural encoding of speech? The OPERA hypothesis. Front Psychol 2:142. CrossRef Medline

Pienkowski M, Eggermont JJ (2012) Reversible long-term changes in auditory processing in mature auditory cortex in the absence of hearing loss induced by passive, moderate-level sound exposure. Ear Hear 33:305314. CrossRef Medline

Poon PW, Chen X (1992) Postnatal exposure to tones alters the tuning characteristics of inferior collicular neurons in the rat. Brain Res 585:391-394. CrossRef Medline

Pungello EP, Iruka IU, Dotterer AM, Mills-Koonce R, Reznick JS (2009) The effects of socioeconomic status, race, and parenting on language development in early childhood. Dev Psychol 45:544-557. CrossRef Medline

Raizada RD, Kishiyama MM (2010) Effects of socioeconomic status on brain development, and how cognitive neuroscience may contribute to levelling the playing field. Front Hum Neurosci 4:3. CrossRef Medline

Raizada RD, Richards TL, Meltzoff A, Kuhl PK (2008) Socioeconomic status predicts hemispheric specialisation of the left inferior frontal gyrus in young children. Neuroimage 40:1392-1401. CrossRef Medline

Roberts JE, Burchinal MR, Zeisel SA, Neebe EC, Hooper SR, Roush J, Bryant D, Mundy M, Henderson FW (1998) Otitis media, the caregiving environment, and language and cognitive outcomes at 2 years. Pediatrics 102:346-354. CrossRef Medline

Rowe ML, Goldin-Meadow S (2009) Differences in early gesture explain SES disparities in child vocabulary size at school entry. Science 323:951953. CrossRef Medline

Sak RJ, Ruben RJ (1981) Recurrent middle ear effusion in childhood: implications of temporary auditory deprivation for language and learning. Ann Otol Rhinol Laryngol 90:546-551. Medline

Salamy A, McKean CM, Buda FB (1975) Maturational changes in auditory transmission as reflected in human brain stem potentials. Brain Res 96 : 361-366. CrossRef Medline

Sanes DH, Constantine-Paton M (1983) Altered activity patterns during development reduce neural tuning. Science 221:1183-1185. CrossRef Medline

Sanes DH, Constantine-Paton M (1985) The sharpening of frequency tuning curves requires patterned activity during development in the mouse, Mus musculus. J Neurosci 5:1152-1166. Medline

Sanes DH, Woolley SM (2011) A behavioral framework to guide research on central auditory development and plasticity. Neuron 72:912-929. CrossRef Medline

Seki S, Eggermont JJ (2003) Changes in spontaneous firing rate and neural synchrony in cat primary auditory cortex after localized tone-induced hearing loss. Hear Res 180:28-38. CrossRef Medline

Sheridan MA, Sarsour K, Jutte D, D’Esposito M, Boyce WT (2012) The impact of social disparity on prefrontal function in childhood. PLoS One 7:e35744. CrossRef Medline 
Siddartha, Bhat V, Bhandary SK, Shenoy V, Rashmi (2012) Otitis media with effusion in relation to socio economic status: a community based study. Indian J Otolaryngol Head Neck Surg 64:56-58. CrossRef Medline

Sininger YS, Doyle KJ, Moore JK (1999) The case for early identification of hearing loss in children. Auditory system development, experimental auditory deprivation, and development of speech perception and hearing. Pediatr Clin North Am 46:1-14. CrossRef Medline

Skoe E, Kraus N (2010) Auditory brain stem response to complex sounds: a tutorial. Ear Hear 31:302-324. CrossRef Medline

Song JH, Skoe E, Banai K, Kraus N (2012) Training to improve hearing speech in noise: biological mechanisms. Cereb Cortex 22:1180-1190. CrossRef Medline

St Clair-Thompson HL (2009) Backwards digit recall: a measure of shortterm memory or working memory? Eur J Cogn Psychol 22:286-296.

Stein RB, Gossen ER, Jones KE (2005) Neuronal variability: noise or part of the signal? Nat Rev Neurosci 6:389-397. CrossRef Medline

Stevens C, Lauinger B, Neville H (2009) Differences in the neural mechanisms of selective attention in children from different socioeconomic backgrounds: an event-related brain potential study. Dev Sci 12:634-646. CrossRef Medline

Strait DL, O'Connell S, Parbery-Clark A, Kraus N (2013) Musicians' en- hanced neural differentiation of speech sounds arises early in life: developmental evidence from ages 3 to 30. Cereb Cortex. Advance online publication. Retrieved September 18, 2013. doi:10.1093/cercor/bht103. CrossRef Medline

Tallal P, Stark RE (1981) Speech acoustic-cue discrimination abilities of normally developing and language-impaired children. J Acoust Soc Am 69:568-574. CrossRef Medline

Tomarken AJ, Dichter GS, Garber J, Simien C (2004) Resting frontal brain activity: linkages to maternal depression and socio-economic status among adolescents. Biol Psychol 67:77-102. CrossRef Medline

Turkheimer E, Haley A, Waldron M, D'Onofrio B, Gottesman II (2003) Socioeconomic status modifies heritability of IQ in young children. Psychol Sci 14:623-628. CrossRef Medline

Woodcock R, Mather N, McGrew K (2001) Woodcock-Johnson III tests of cognitive abilities examiner's manual. Itasca, IL: Riverside.

Zhang LI, Bao S, Merzenich MM (2002) Disruption of primary auditory cortex by synchronous auditory inputs during a critical period. Proc Natl Acad Sci U S A 99:2309-2314. CrossRef Medline

Zhou X, Merzenich MM (2012) Environmental noise exposure degrades normal listening processes. Nat Commun 3:843. CrossRef Medline 